\title{
STENSIL SEBAGAI MEDIA ASPIRASI DALAM WACANA DESAIN KOMUNIKASI VISUAL
}

\author{
Antonius Purwantono \\ Mahasiswa Program Studi Disain Komunikasi Visual, \\ Jurusan Disain, FSR ISI Yogyakarta \\ Email: antonius01pur@gmail.com
}

\begin{abstract}
Stencil is one of street art forms such as mural and graffity. It's simplicity and the people/community perceptions towards the street art have made stencil as a medium for street art artist to express their ideas. Today, stencil becomes the form of street art practices and is used as visual design elements wich can be applied as profitable commodity.
\end{abstract}

Keywords : Street art, stencil, ideas, application

\section{Pendahuluan}

Waktu berjalan tanpa kompromi, membawa kita merasakan geliat evolusi/revolusi dalam sendi-sendi kehidupan di negara ini. Perubahan yang sering menuai pro dan kontra akan selalu ada sebagai bentuk "bunga-bunga" atas berbagai macam tujuan, rencana, kebijakan, keputusan, amanat, amanah, peraturan, yang dibuat oleh pemerintah. Sekolah mahal, pangan mahal, sakit mahal, birokrasi semrawut, pelayanan publik buruk, pengangguran, kemiskinan, hukum yang terbeli, keamanan, kekerasan, korupsi merajalela, begitu akrab menyapa kita melalui berbagai media. Kesemuanya itu tentu saja menuai berbagai respon dari masyarakat akar rumput hingga masyarakat atas. Atas nama demokrasi, masyarakat dengan mudah dapat menyampaikan

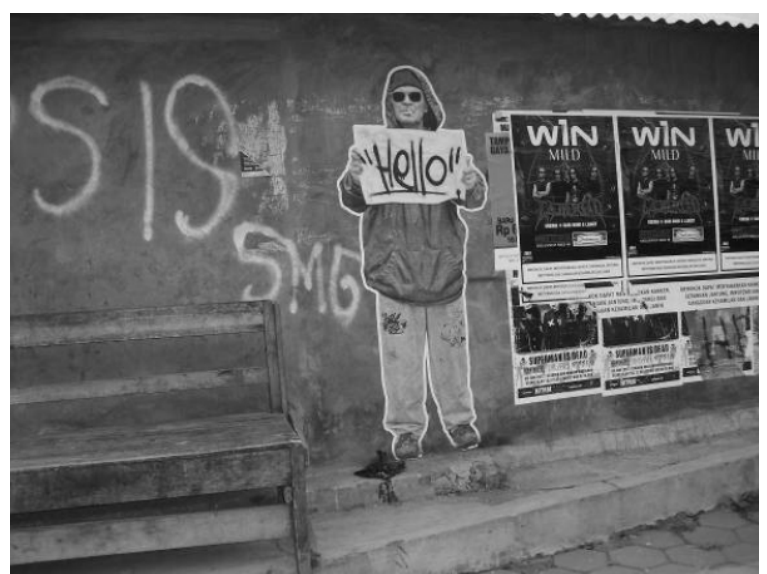

berbagai macam aspirasinya sebagai tanggapan atas hal tersebut. Setiap orang atau kelompok memiliki cara yang berbeda-beda dalam penyampaiannya.

Para seniman street art memiliki cara tersendiri dalam menanggapi isu-isu yang tengah marak di dalam masyarakat. Ruang publik, sebuah ruang yang bersinggungan langsung dengan kepentingan umum menjadi media pilihan tatkala media-media mainstream kurang memberikan ruang atau cenderung diametral dengan muatan pada karya yang ingin mereka sampaikan. Karyakarya street art seakan menjadi "make up" pemanis jalanan di antara goresan-goresan vandalisme serta polesan iklan luar ruang yang dipasang berdesak-desakan pada baliho, poster, billboard, dsb.

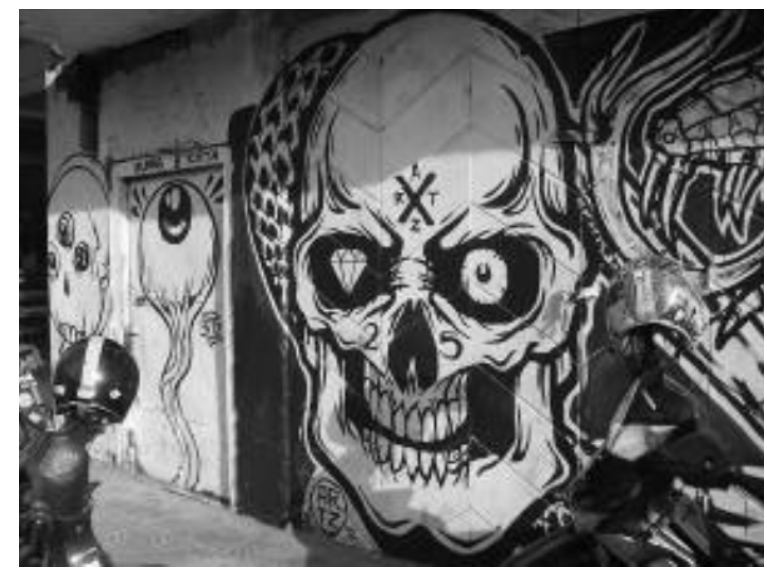

Gambar 1 : Street art di jalanan Muntilan (kiri) dan Yogyakarta (kanan) (Sumber : Dokumentasi penulis) 
Sesuatu yang cukup menarik dan sering kita jumpai adalah poster-poster hitam putih bergaya stensil yang ditempel maupun yang langsung disemprotkan pada tembok, pagar, maupun dinding di sepanjang jalan perkotaan. Sebagian besar tentang hal-hal yang bersifat kritis, aspiratif, opini dsb. Sebuah bentuk komunikasi kasat mata (visual) atas tanggapan beragam isu yang dikemas dalam bentuk ilustrasi maupun tipografi. Tak jarang pula kehadirannya mengundang senyum bagi siapa saja yang melihat meskipun hanya sepintas saja.

Dalam dinamika masyarakat kontemporer dimana pertukaran informasi dapat dilakukan dengan mudah yang diikuti pula oleh transformasi budaya di dalamnya, praktik-praktik stensil tidak hanya dilakukan oleh mereka yang benar-benar dalam lingkup bidang tersebut (seniman) namun juga oleh sebagian orang di luar lingkup tersebut. Aktifitas tersebut bisa dikatakan (hanya) menjadi sebuah gaya hidup bagi sebagian orang atau kelompok tertentu.

Gaya hidup dipahami sebagai cara-cara terpola dalam menginvestasikan aspek-aspek tertentu dari kehidupan sehari-hari dengan nilai sosial atau simbolik. Dengan demikian gaya hidup menjadi cara untuk mengidentifikasikan diri dan sekaligus membedakan diri dalam relasi sosial. Gaya hidup juga menjadi cara bermain dengan identitas (Subandy, 2011: 307). Hal tersebut sedikit bisa kita lihat dari sejauh mana 'kualitas' serta muatan yang terkandung di dalam karyakaryanya.

Apapun yang terkandung di dalamnya serta siapapun pelakunya akan menjadi hal yang sangat menarik jika kita mengkaji stensil lebih jauh, namun untuk mudahnya kita bisa membedakannya terlebih dahulu antara stensil sebagai proses (teknik) dalam penciptaan sebuah karya dengan stensil yang dimaknai sebagai sub dari street art.

\section{Stensil}

Stensil adalah lembaran material tipis, biasanya terbuat dari bahan plastik, kertas atau logam (plat) namun tidak menutup kemungkinan terbuat dari bahan-bahan diluar itu. Stensil digunakan untuk membuat tulisan atau gambar pada media yang mendasari dengan menyemprotkan pigmen pada lubang yang telah dibuat sebelumnya. Efektifitas penggunaan stensil adalah dapat digunakan berulang kali serta dapat digunakan dengan cepat untuk me-(re)-produksi sebuah desain yang seragam.

Agar dapat digunakan kembali, desain yang telah dibuat pada stensil harus tetap utuh setelah dilepas dari media kerja. Teknik stensil dalam seni rupa disebut juga dengan pochoir, sedangkan teknik-teknik terkait lain (yang telah ditemukan dalam penerapannya pada komposisi surealis) adalah areography. Areography adalah teknik dimana pigmen disemprotkan pada sebuah obyek tiga dimensi untuk membuat negatif dari obyek tersebut bukan positifnya seperti pada teknik stensil (kebalikan dari teknik stensil). Teknik ini ditemukan pada sebuah lukisan gua di dinding gua di Rio Pinturas Argentina yang berusia antara 30.000-10.000 SM atau lukisan serupa di dinding Gua Tewe, Kutai Timur, Kalimantan Timur, juga di gua Pangkep, Maros Sulawesi Selatan dan pantai di bagian selatan Papua berupa lukisan berbentuk tangan. Penelitian mengatakan bahwa manusia pada masa itu menggunakan tangannya sendiri sebagai media cetak dan tulang binatang untuk menyemprotkan pigmen dengan cara meniupnya.

\section{Sejarah Stensil}

Lukisan stensil berupa gambar-gambar tangan umum ditemukan pada masa prasejarah. Sejak lama, teknik stensil juga digunakan untuk pewarnaan pada kain; puncaknya adalah pada Katazome dan juga teknik lain pewarnaan sutera pada era Edo di Jepang.

Sejak tahun 1450 teknik stensil umum digunakan pada masterprint (mal) cukilan kayu yang diberi warna hitam putih. Setelah teknik pewarnaan hitam putih ditinggalkan teknik tersebut banyak digunakan untuk pewarnaan kartu remi. Selain itu dulu teknik tersebut juga sering digunakan untuk publikasi massa karena praktis (tidak perlu tulisan tangan). 

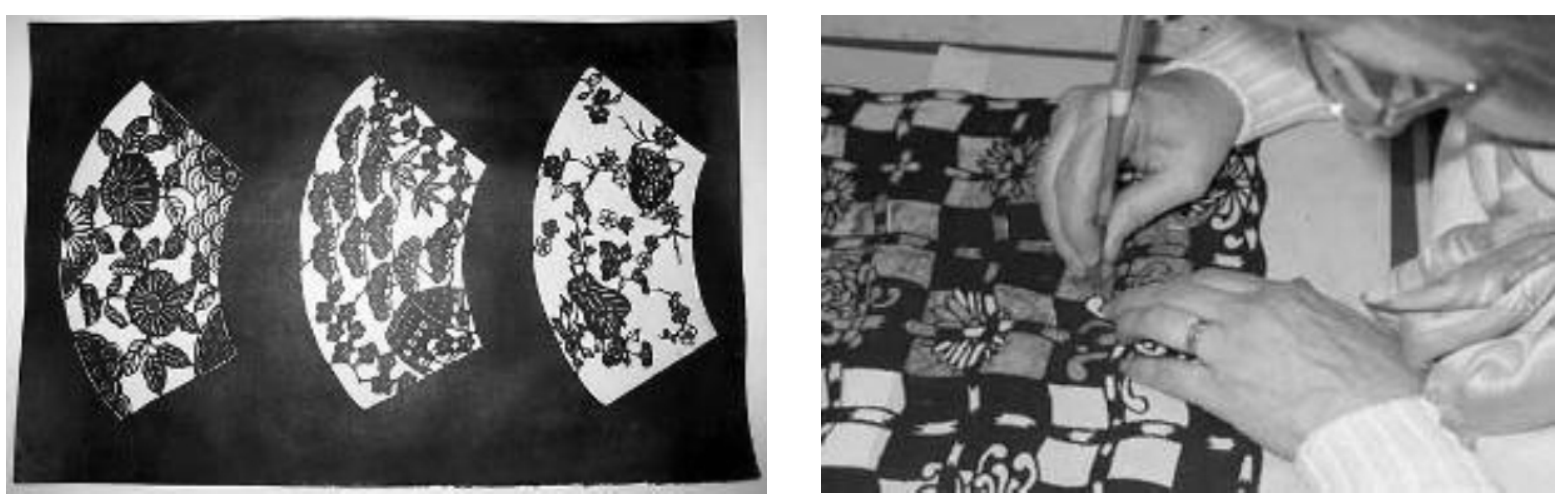

Gambar 2. Katazome Stensil

(Sumber: http://www.nautilus-fiberarts.com/NewNFA/01AboutKatazome)

Teknik stensil untuk ilustrasi buku banyak digunakan sejak tahun 1920 di Perancis, terutama ketika André Marty, Jean Saudé dan studio-studio di Paris menggunakan teknik tersebut. Upah buruh yang rendah membuat teknik stensil menjadi pilihan dan berkembang pesat karena proses kerja yang intensif. Proses kerja inilah yang dinamakan pochoir (seperti yang ditulis pada pembahasan di atas), dimana setelah outline desain dibuat maka serangkaian stensil digunakan secara manual pada bagian buku yang akan diberi ilustrasi. Kemudian untuk membuat detail yang diinginkan digunakanlah collotype (Cetak collotype adalah suatu cetak secara foto mekanis yang dipakai untuk memproduksi foto-foto dan lukisan.) setelah proses pewarnaan dengan teknik stensil selesai. Pochoir sering digunakan untuk blok-blok warna dan paling sering dikaitkan pada aliran Art Nouveau dan Art Deco. lain. Untuk membuat outline ilustrasi maupun tipografi digunakanlah mal yang terbuat dari plastik, kertas, kardus, kayu dsb. Stensil digunakan juga oleh lembaga pemerintahan dan militer untuk memberi label secara cepat dan jelas terhadap barang-barang, kendaraan dan sign system lokasi tertentu. Label-label stensil umum digunakan secara langsung atau dijual secara terpisah misalnya huruf, angka atau simbol tertentu sehingga dengan begitu seseorang bisa menggunakan sesuai keinginannya.

\section{Seni Stensil Graffiti}

Stensil dalam bab ini dimaknai sebagai jenis atau sub dari street art sebagaimana dikutip dari artikel "Dari Street Art, Satpol PP hingga Pilkada". Street art identik dengan seni rupa jalanan, dimana penempatannya wajib bersinggungan dengan khalayak agar pesan-
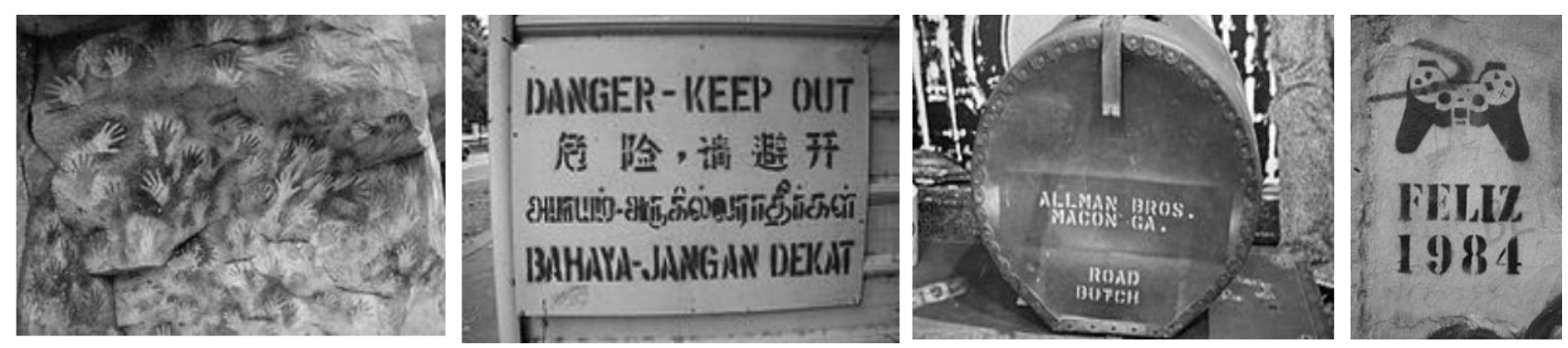

Gambar 2. Katazome Stensil

(Sumber: http://www.nautilus-fiberarts.com/NewNFA/01AboutKatazome)

Stencil aerosol yang cukup praktis sering digunakan pada industri, perdagangan, tempat rekreasi, perumahan, dekorasi seni, militer, pemerintahan, manajemen infrastruktur, dan lain pesannya tersalurkan. Bentuk-bentuk seni yang dipopulerkan di New York tahun 1980an ini diterjemahkan ke dalam banyak jenis, misalnya grafiti, mural, stencil dan sebagainya yang 
diantaranya memiliki karakter pengerjaan berbeda-beda (Kuwado, 2012) Street art atau seni jalanan sebenarnya tidak berbeda dengan dengan graffiti namun dalam pengertian sempit kata graffiti selalu mengacu pada 'graffiti hip hop' yang mengacu pada tags (semacam tanda tangan) dan pieces (karya graffiti) yang mulai muncul pada tahun 1960-an di New York. Oleh karena itu kemudian pada tahun 1980-an muncul istilah street art untuk menyebut jenis karya seni lain yang juga muncul di jalanan namun lepas dari pengaruh gaya hip hop. Istilah ini mulai dikenal melalui karya-karya Keith Haring, Kenny Scharf, Basquiat, Blek dan Nemo (Bajragosa, 2009: 125) Stensil banyak digukanan oleh artis graffiti karena dapat dilakukan secara cepat dan mudah, hal ini karena seni graffiti bisa saja legal maupun ilegal tergantung peraturan dari setiap negara. Seni Graffiti dengan teknik stensil pada awalnya banyak digunakan untuk tujuan politis. Sebagai

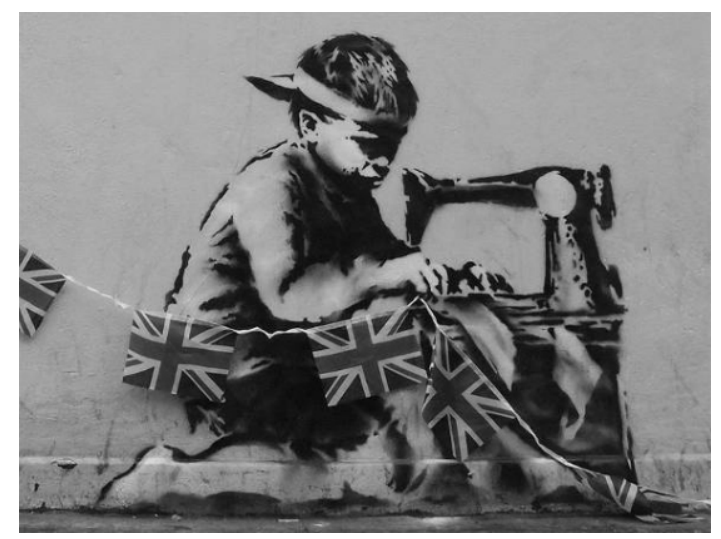

contoh band anarcho-punk Crass menyampaiknn pesan-pesan tentang anti perang, anarkisme, feminisme, melalui graffiti yang dilakukan pada fasilitas bawah tanah London serta billboardbilboard iklan. Adapun artis-artis yang terkenal dengan penggunaan stencil art antara lain; Blek le Rat dan Jef Aerosol dari Prancis, seniman Inggris Banksy, seniman New York Yohanes Fekner, serta artis yang berkeliling dunia Above, dan Shepard Fairey's OBEY.

Tidak hanya di dunia barat, seni stensil di Indonesia muncul pada awalnya di Jakarta, Yogyakarta, Bandung dan akhirnya menyebar hampir ke seluruh kota-kota di Indonesia. Jakarta antara lain; Reflect, Stenzila, Totter, UBC. Bandung antara lain; Hope, Noah, Kampret Zyndicate. Yogyakarta; Anti Tank, Here Here, Love Hate Love, Methodos, Tembok Bomber dlsb. Para seniman tersebut kesemuanya memiliki ciri khas tersendiri dalam berkarya.

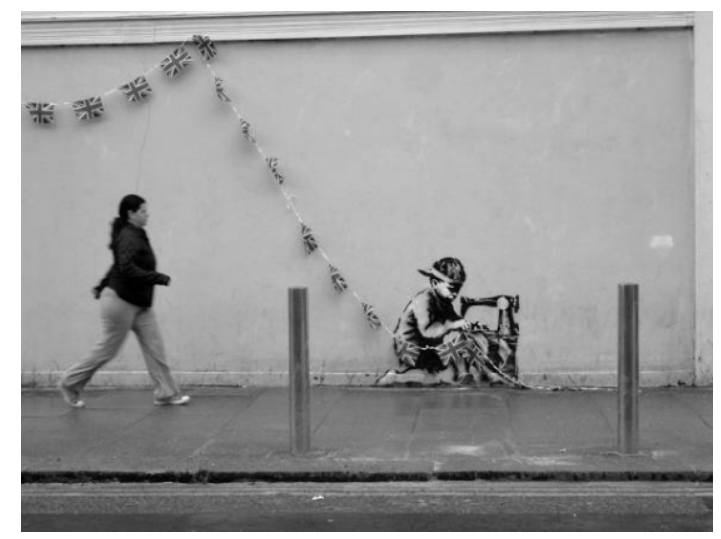

Gambar 4. Seni Stensil karya Banksy

(Sumber: www.banksy.co.uk)
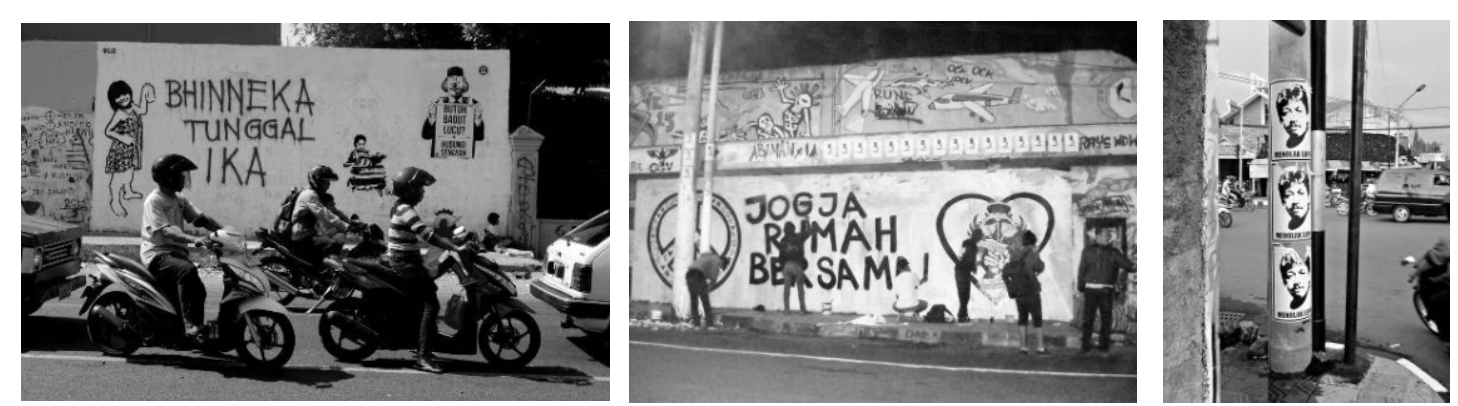

Gambar 4. Beberapa contoh karya seniman Yogyakarta 


\section{Stensil Sebagai Media Aspirasi dan Ekspresi}

Masyarakat yang telah lama menganggap karya seni itu teratur, seperti seni lukis, seni pahat, desain, yang biasa dinikmati dalam literatur, galeri maupun pasar seni. Kenyataan inilah yang membuat masyarakat menganggap street art cenderung ke arah vandal, merusak kepentingan publik dsb. Kurangnya pemahaman pemerintah terhadap gaya seni ini mengakibatkan terjadinya kontradiksi antara aktifitas seniman jalanan dengan persepsi penguasa yang ingin wajah kotanya terlihat rapi, bersih dan tertata. Padahal para pimpinan kota sendiri melalui badan terkait terkadang tidak memperhatikan estetika tata kota dalam pemasangan atribut baliho, sepanduk dan media lainnya.

Tembok-tembok, tiang listrik, pagar dan terkadang instalasi publik menjadi arena "bermain" para seniman street art. Tanpa disadarai atau tidak, tempat-tempat tersebut memiliki hubungan langsung dengan kepentingan publik baik secara historis maupun fungsional. Kenyataan inilah yang diharapkan menjadi diferensiasi antara seniman street art dengan pelukis, misalnya. Mereka semestinya tidak memandang media yang mereka gunakan dalam berkarya seperti layaknya kanvas bagi para pelukis. Mereka tidak lantas dengan "semenamena" menjadikan media tersebut sebagai wadah berekspresi yang seluas-luasnya.

Sebagaimana dengan publik sebagai unsur di dalamnya. Para street artis juga harus mampu menjadikan publik sebagai subjek, bukan hanya obyek pasif. Kepekaan terhadap ruang sangat diperlukan, karena keindahan dalam street art tidak melulu dilihat dari gambaran karya yang dihadirkan, lebih dari itu: mereka harus 'kontekstual', memiliki muatan yang jelas sehingga tidak hanya dianggap sebagai karya dekoratif ataupun dari sisi lain disamakan dengan vandalisme.

Street art bisa dikatakan telah menjadi budaya visual di negara ini, bukan lagi sub dari budaya visual lagi. Budaya visual menurut menurut Agus Schari adalah tautan kebudayaan konsep (nilai) dan kebudayaan materi (benda) yang dapat ditangkap oleh indera visual (mata), dan dapat dipahami sebagai model pikiran manusia untuk dapat meningkatkan taraf hidupnya (Sachari, 2007:1) Indikasinyapun jelas bahwa street art di Indonesia bisa dikatakan telah diakui, buku-buku yang membahas street art banyak di cetak, pun penelitian mengenainya tak jarang dilakukan serta adanya banyak even yang telah terselenggara meliputi tingkat daerah nasional dan internasional. Berbeda misalnya dengan stikerstiker motor ataupun lukisan truk, contohnya, setiap karya street art bahkan memiliki nama pelaku yang jelas. Street art masih lebih banyak diwacanakan, dari sini kita bisa melihat adanya pertukaran pengetahuan di dalamnya, sebagai sebuah ilmu.

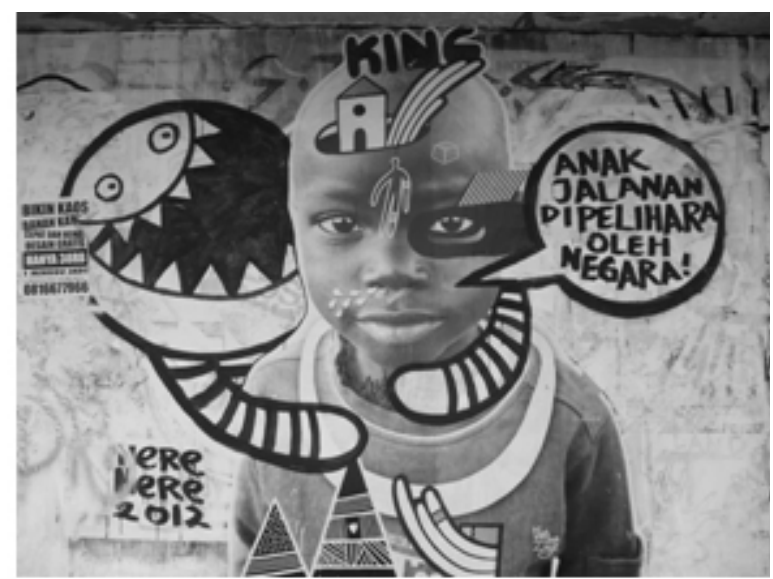

Gambar 5 : Stensil di Yogyakarta

(Sumber: Dokumentasi penulis) 
Kemudahan dan kecepatan penggunaan stensil dan kondisi persepsi publik terhadap street art menjadikan stensil sebagai pilihan para seniman jalanan dalam menyampaikan aspirasi dan ekspresi. Stensil disatu sisi tetap mempertahankan kemungkinan me-(re)-produksi gambar (imaji) tanpa mensyaratkan kemampuan (akademis) yang kompleks dan sisi lain menanggapi kebutuhan akan fleksibelitas gerak yang diperlukan pada praktik "gerilya visual". Russel Howze manganggap stensil sebagai medium perantara ditengah graffiti dan mural. Stensil dapat direproduksi dengan cepat kesejumlah tempat, atau disusun repetitif untuk memenuhi bidang yang luas disuatu tempat. Seni stensil menawarkan kompleksitas tapi juga keleluasan gerak pada praktisinya. Dalam perkembangannya, stensil telah menjadi medium "seni rupa bawah" (baca: low brow) yang berkembang cepat dengan bantuan internet. Metode visualnya juga telah dipungut oleh seniman berlatar belakang akademis (Agung, 2011). Penggunaan blok wana (biasanya hitam) pada latar belakang putih membuat tampilan itu, kemudahan teknologi dan informasi sekarang ini juga membuat stensil lebih beragam dan menarik.

\section{Stensil Pada Aplikasi Desain}

Aktifitas para seniman street art tidak hanya sebatas pada 'gerilya' visual saja. Di sisi lain mereka juga melakukan hal yang sifatnya 'menjual'. Berbagai merchandise; kaos, tas, mug dsb. Mereka menawarkannya pada situs-situs maupun ketika ikut serta dalam sebuah pameran. Sedangkan aktifitas mereka dijalanan dengan sendirinya telah menjadi media 'promosi' untuk 'menawarkan' produk-produknya meskipun pada dasarnya di tiap karya mereka tidak ada tendensi untuk membujuk orang mengkonsumsi sesuatu atau mengajak untuk membeli.

Seperti halnya ragam seni/desain, gaya visual, dan aplikasi kreatifitas visual yang muncul dalam berbagai penampilan visual di dalam masyarakat, stensilpun sering digunakan sebagai bagian dari unsur-unsur desain. Layaknya penggunaan gaya desain;psycheelic, punk, dada, art nouveau dsb., dalam trend retro saat ini,

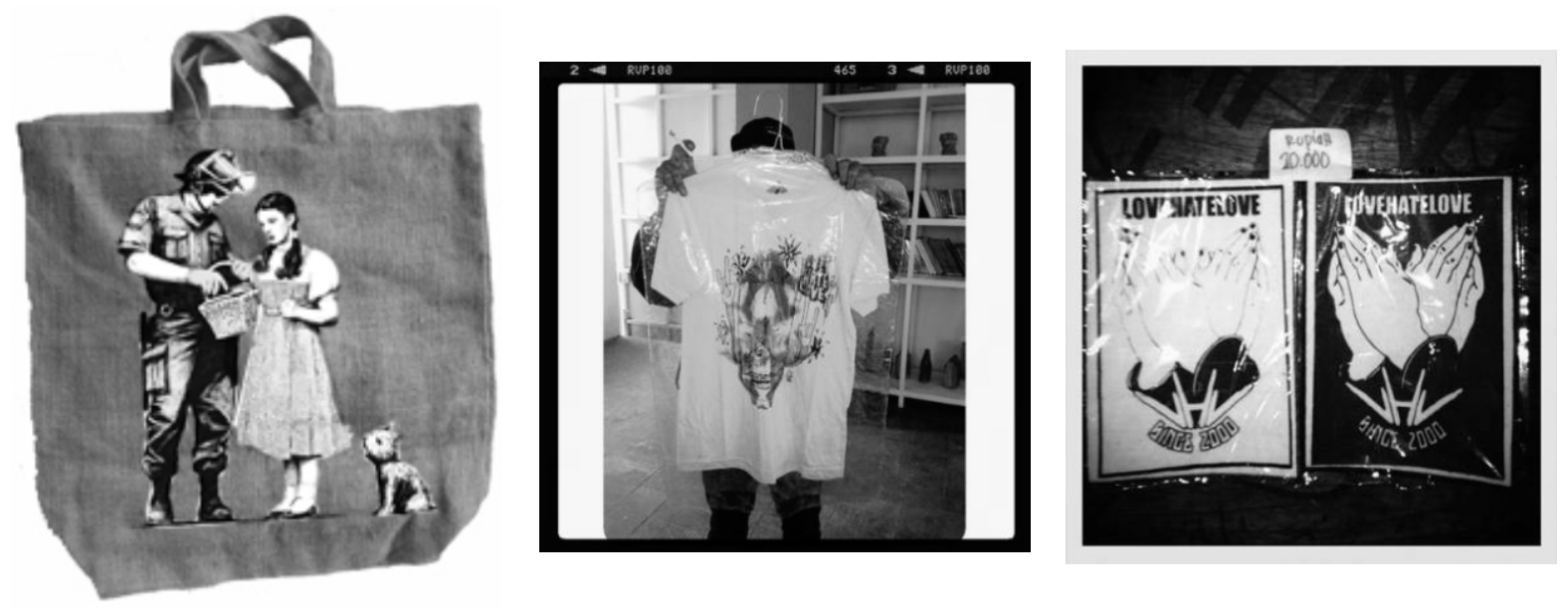

Gambar 6 : dari kiri karya Banksy dan Love Hate Love

stensil terlihat kontras dan dengan sendirinya memiliki stopping power bagi masyarakat yang melintas di dekatnya. Penggunaan ilustrasi serta pemiliihan tipografi yang "unik" semakin menarik perhatian, terlebih lagi sebagian besar berisi tentang tanggapan terhadap isu-isu yang tengah marak (up to date) dinegara ini; kenaikan BBM, korupsi, terorisme, pendidikan dlsb. Tidak hanya penggunaan teknik/gaya stensil bisa menghadirkan/menampilkan/ memvisualkan nuansa jalanan. Nuansa 'pembangkangan' dimana kebebasan beraspirasi serta berekspresi bisa dasampaikan dengan tegas dan dikemas dengan sesuatu yang simple (to the point).

Kecenderungan generasi sekarang yang kritis terhadap segala macam isu yang tengah 
terjadi menjadi aspek bagi pihak-pihak korporasi untuk menggunakan teknik/gaya stensil sebagai sesuatu (komoditi) yang (bisa) menjual. Disinilah peran korporasi menanggapi apa yang disebut dengan budaya tanding. Hal tersebut (meskipun tidak mutlak) dapat di korelasikan dengan fenomena kaum hippies di Amerika.

Generasi pertama hippies berbuat sebisanya untuk melanggar tatakrama berbusana masyarakat tahun 1850-an; yang lelaki memanjangkan rambut juga cambang, tidak mau mengenakan kemeja dan dasi; yang perempuan memakai rok mini, mencopot kutang, berhenti berias, dan seterusnya.

Namun tak lama kemudian aneka aksesoris dan gaya dandanan inipun mulai bermunculan dalam iklan-iklan dan di manekin jendela-jendela toko. Dengan cepat toserbatoserba pun menjual medali-medali perdamaian dan manik manik cinta. Dengan kata lain, "sistem" sepertinya menganggap hippies lebih sebagai peluang menjual ketimbang ancaman terhadap kemapanan. Awalnya, sistem hanya mencoba mengasimilasi perlawanan dengan mencaplok simbol-simbolnya, mengosongkan muatan "revolusioner"-nya dan menjualnya balik ke massa sebagai komoditas (Heat; Potter, 2009).

Ada banyak sekali aplikasi-aplikasi (kadang) hanya sebatas pada penggayaan saja. Tata letak/layout, gaya visual, metode/teknik visualisasi unsur-unsur desain seperti jenis tipografi, warna, susunan hirarki visual ataupun makna pesan-pesan itu sendiri dilakukan dengan bantuan teknologi percetakan misalnya, sehigga makna/rasa/nuansa dari stensil tersebut masih bisa dimunculkan dengan tidak mengalami banyak kendala dalam prosesnya.

\section{Kesimpulan}

Stensil tidak hanya sebatas street art, namun lebih dari itu, stensil memberikan kontribusi yang cukup besar terhadap perkembangan desain di Indonesia. Stensil juga memberikan alternatif tersendiri dalam desain komunikasi visual serta menambah khasanah desain di Indonesia. Keberadaan stensil memberikan sentuhan tersendiri di temboktembok serta dinding perkotaan. Diantara teriakan-teriakan iklan luar ruang yang berlombalomba mencari perhatian, stensil masih bisa berteriak meskipun lirih, menggugah kita semua untuk lebih peka terhadap isu-isu yang ada di negara ini.

Terlepas dari cap sebagian masyarakat yang menganggap stensil sebagai vandalisme, seyogyanya pemerintah bisa mengadaptasi stensil
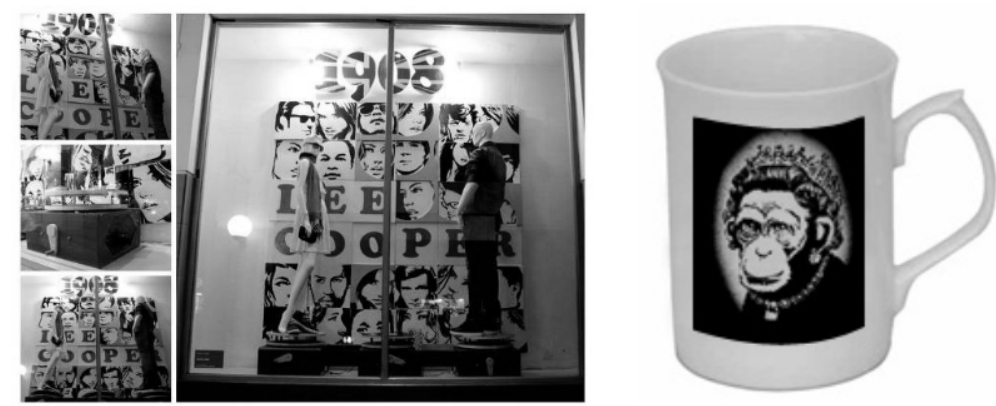

Gambar 7. Aplikasi stensil pada window display dan mug

stensil pada desain yang bertujuan sebagai komoditi yang menjual atau sarana untuk meningkatkan penjualan; window display, packaging, interior, sign system, web, dsb. Efektifitas sebagai tuntutan dalam produksi massal menjadikan pemakaian stensil digunakan sebagai solusi dalam hal estetika tata kota. Sehingga tercipta hubungan yang harmonis antara pemerintah, masyarakat dan seniman street art. Begitu juga dalam lingkup akademisi, stensil akan selalu menjadi obyek visual yang menarik untuk dikaji dan dibagi. 


\section{Kepustakaan}

Bajragosa, Terra, Sekilas Mengenai Logo Jalanan dalam Irama Visual, Dari Tukang Reklame Sampai Komunikator Visual, Jalasutra, Yogyakarta, 2009

Heat, Joseph and Andrew Potter, Radikal Itu Menjual, Budaya Perlawanan Atau Budaya Pemasaran?, Antipasti, Jakarta, 2009

Sachari, Agus, Budaya Visual Indonesia, Penerbit Erlangga, Bandung, 2007

Subandy, Ibrahim Idi, Kritik Budaya Komunikasi Budaya, Media dan Gaya Hidup dalam Proses Demokratisasi di Indonesia, Jalasutra, Yogyakarta, 2011

\section{Internet}

http://puslit.petra.ac.id/journals/design/ Retro Sebagai Wacana dalam Desain Komunikasi Visual, Andrian Dektisa Hagijanto, Dosen DKV Fakultas Seni dan Desain - Universitas Kristen Petra

http://www.tembokbomber.com/category/stencil/ http://megapolitan.kompas.com/read/2012/04/22/ 09534394/Dari.Street.Art.Satpol.PP.Hingga. Pilkada

http://www.indonesiakreatif.net/index.php/id/ne ws/read/1478

http://award.indonesianstreetartdatabase.org/

http://en.wikipedia.org/wiki/Stencil

http://indonesiaartnews.or.id/artikeldetil.php?id= 95 